УДК 621.43

DOI: $10.35887 / 2305-2538-2021-5-24-34$

ПЕРСПЕКТИВНЫЕ ДВИГАТЕЛИ ДЛЯ АВТОТРАКТОРНОЙ ТЕХНИКИ

\author{
${ }^{1}$ Ломовских Александр Егорович \\ ${ }^{2}$ Сазонов Сергей Николаевич \\ ${ }^{1}$ Новичихин Виталий Васильевич \\ ${ }^{1}$ Калинин Никита Сергеевич \\ ${ }^{1}$ Машин Владимир Алексеевич \\ ${ }^{1}$ ФГКВОУ ВО «ВУНЦ ВВС «ВВА им. проф. Н.Е. Жуковского и Ю.А. Гагарина» \\ ${ }^{2}$ Администрация Тамбовской области
}

Реферат: Внедрение высокоэффективных силовых агрегатов для автотракторной техники является актуальной задачей, решение которой позволит в иелом повысить экономические и экологические характеристики данной техники. В статье представлены перспективные силовые установки для автотракторной техники. По мнению авторов, наиболее перспективен силовой агрегат для автотракторной техники, разработанный под руководством профессора Воробьева Ю.В. Многоиелевой роторно-поршневой двигатель (РПД) с круговым параллельным движением ротора-поршня совмещает особенности традиционного поршневого ДВС и альтернативного РПД. Опытный образец роторно-поршневого двигателя подтвердил работоспособность представленной конструкции. В ходе его эксплуатации установлено что достигнута заданная степень сжатия (8,5) при 3400 об/мин. Расход топлива на холостом ходу аналогичен этому параметру у мотора ВАЗ 2106 с таким же карбюратором и аналогичным рабочим объемом. Выявлены преимущества двигателя, по сравнению с аналогами: возможность изменения степени сжатия; возможность использования метало-керамических материалов, для существенного снижения расхода топлива и токсичности отработавших газов за счет дискретного изменения его рабочего объема и, соответственно, повышения КПД такого ДВС; повыменная герметичность рабочих камер за счет внедрения перспективной конструкции разделительной пластины лопасти. Предложены перспективные технологии к использованию в поршневых ДВС, позволяюшче снизить удельный расход топлива ДВС до 15\%; уменьшить удельный вес до 30\%; увеличить ресурс в 2 раза; снизить вредные выбросы от выхлопных газов двигателей до 40\%. Показаны направления для дальнейшего развития двигателей.

Ключевые слова: двигатели внутреннего сгорания, перспективная силовая установка, эксплуатационные показатели двигателя, автотракторная техника, экономические и экологические характеристики двигателей.

\title{
PROMISING ENGINES FOR AUTOMOTIVE EQUIPMENT
}

\author{
${ }^{1}$ Lomovskih Alexandr \\ ${ }^{2}$ Sazonov Sergey \\ ${ }^{1}$ Novichikhin Vitaly \\ ${ }^{1}$ Kalinin Nikita \\ ${ }^{1}$ Mashin Vladimir \\ ${ }^{1}$ Military educational scientific center air force "air force Academy \\ named after Professor N. E. Zhukovsky and Y. A. Gagarin», \\ ${ }^{2}$ Administration of the Tambov region
}

\begin{abstract}
The introduction of highly efficient power units for automotive vehicles is an urgent task, the solution of which will generally improve the economic and environmental characteristics of this equipment. Perspective power plants for automotive vehicles are presented in the article. According to the authors, the most promising power unit for automotive vehicles, developed under the guidance of Professor Yu.V. Vorobyov. The multipurpose rotary piston engine (RPE) with circular parallel movement of the rotorpiston combines the features of a traditional piston internal combustion engine and an alternative RPE.
\end{abstract}


The prototype of the rotary piston engine confirmed the performance of the presented design. During its operation, it was found that the specified compression ratio (8.5) at $3400 \mathrm{rpm}$ was achieved. Fuel consumption at idle speed is similar to this parameter for a VAZ 2106 engine with the same carburetor and a similar displacement. The advantages of the engine in comparison with analogues are revealed: the possibility of changing the compression ratio; the possibility of using metal-ceramic materials to significantly reduce fuel consumption and toxicity of exhaust gases due to discrete changes in its working volume and, accordingly, increase the efficiency of such an internal combustion engine; increased tightness of the working chambers due to the introduction of a promising design of the blade separation plate. Prospective technologies have been proposed for use in piston internal combustion engines, which make it possible to reduce the specific fuel consumption of internal combustion engines by up to $15 \%$; reduce the specific gravity up to 30\%; increase the resource by 2 times; reduce harmful emissions from engine exhaust gases up to 40\%. Directions for further development of engines are shown.

Keywords: internal combustion engines, advanced power plant, engine performance indicators, automotive equipment, economic and environmental characteristics of engines.

Введение. В настоящее время привод автотракторной техники и специального оборудования (АТT) осуществляется от силового агрегата, в качестве которого используются бензиновые и дизельные поршневые двигателей внутреннего сгорания (ДВС), эксплуатация которых в значительной степени определяет в целом эксплуатационные характеристики АТТ. Поэтому разработка и внедрение высокоэффективных двигателей для ТС является актуальной научной задачей, решение которой позволит в целом повысить экономические и экологические характеристики АТТ. Решение данной задачи должно выполняться с учетом концептуальных положений, заложенных в стратегии развития автопрома РФ на период до 2025 года, где в качестве приоритетных направлений инновационного развития выбраны [1]:

- улучшение энергоэффективности и повышение экологических показателей ДВС;

- технологии экологической безопасности (альтернативные виды топлива и др.).

Материалы и методы. На сегодняшний момент в результате локализации сборочных производств иностранных автопроизводителей привело к сокращению производственных мощностей отечественных автомобильных заводов.

Таблица 1 - Мировые тенденции развития перспективных ДВС

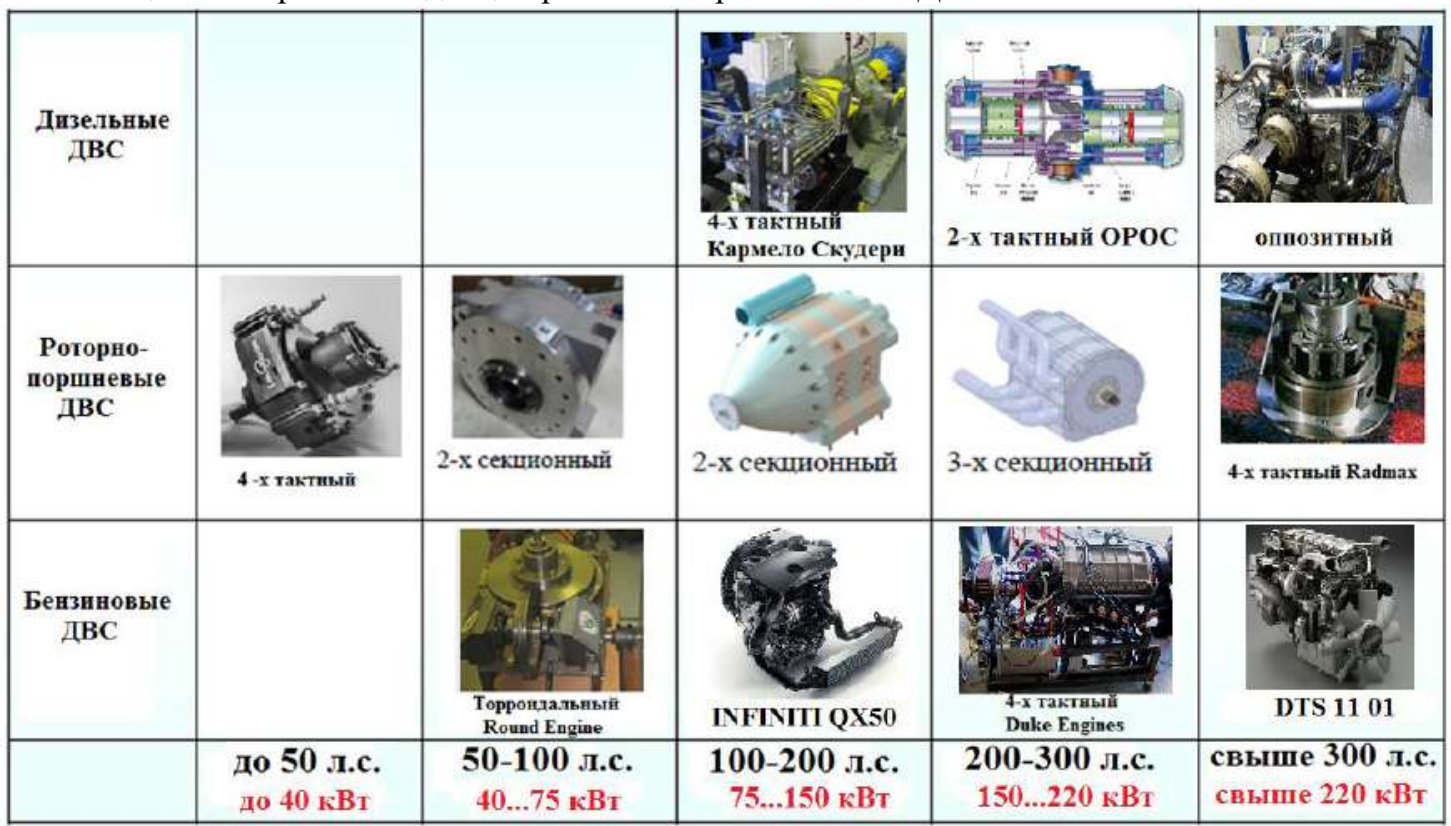


В результате этого сложилось и неблагополучное состояние для двигателестроительных предприятий нашей страны, к которому можно отнести:

- $\quad$ банкротство и перепрофилирование двигателестроительных предприятий, а также ведущих организаций отраслевой науки;

- $\quad$ отсутствие развития отечественных специализированных производств;

- $\quad$ потеря квалифицированных кадров научного персонала, конструкторов и т.д.;

- $\quad$ неуклонно снижающийся уровень подготовки квалифицированных кадров для двигателестроения.

Мировые и отечественные тенденции развития перспективных ДВС, представлены в таблице 1, по направлениям - дизельные, роторно-поршневые и бензиновые двигатели, в зависимости от их мощностных характеристик от 40 кВт и свыше 220 кВт [2, 3].

Следует отметить, что в таблице 1 представлены двигатели, опытные образцы которых, на сегодняшний момент, прошли испытания.

Первый образец. Двухтактный дизельный двигатель ОРОС (Opposed Piston Opposed Cylinder) производство США (рисунок 1), представляет собой два поршня в одном цилиндре, движущиеся навстречу друг другу. Такая схема двигателя позволяет применить только один коленчатый вал, что делает такой ДВС более компактный и легкий по сравнению с конкурентами.

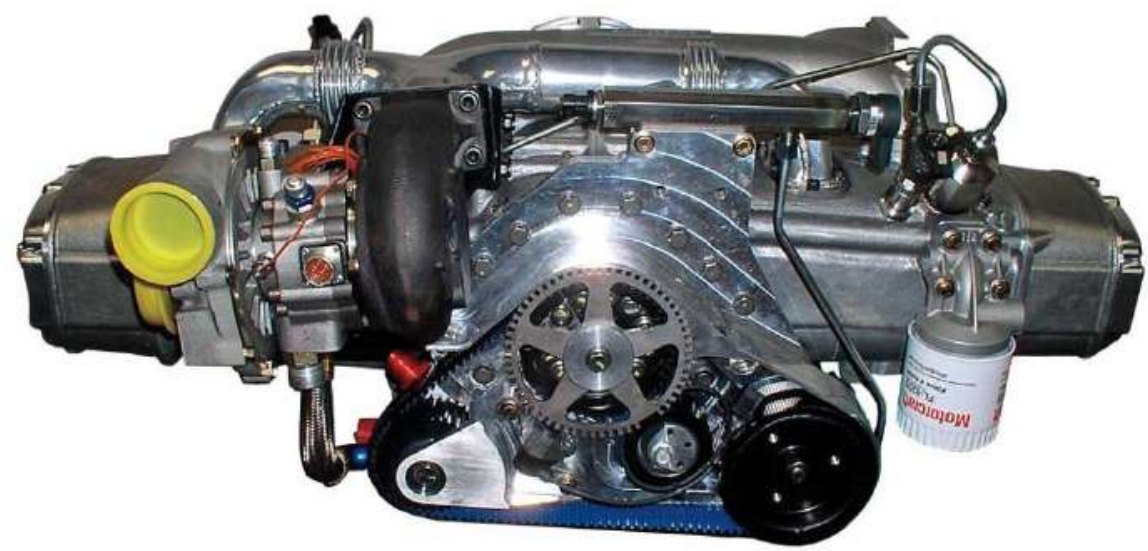

Рисунок 1 - Внешний вид ДВС «ОРОС»

Этот двигатель изначально предназначен для армии США. Его опытный образец развивает мощность в 325 л.с. при массе в 143 кг. В итоге по массе он на 30...50\% легче подобных по мощности дизельных двигателей, в добавок он еще и в 2...4 раза компактнее.
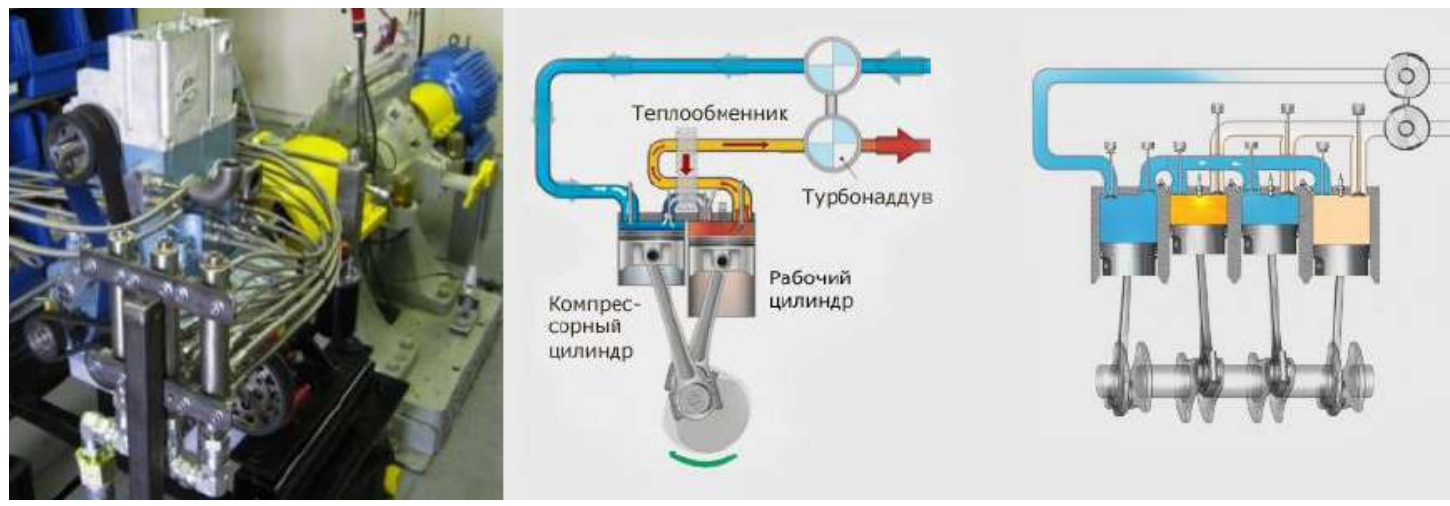

Рисунок 2 - Внешний вид двигателя «Кармело-Скудери» 
Второй образец. Двигатель американской компании Scuderi Group - двигатель КармелоСкудери, внешний вид такого двигателя представлен на рисунке 2.

В разработанном в США ДВС под названием «Кармело-Скудери» имеются классические четыре такта (впуск-сжатие-рабочий ход-выпуск) распределены между двумя цилиндрами. При этом как видно из рисунка 2 впуск и сжатие происходят в одном цилиндре, а рабочий ход и выпуск в другом компрессорном цилиндре.

За один оборот коленвала в таком двигателе происходят все 4 такта, следовательно, в 2 раза быстрее, чем в обычном двигателе.

Как заявляет производитель, двигатель Скудери на 25\% экономичнее обычного, а мощность составляет 135 л.с. (100 кВт) с литра рабочего объема.

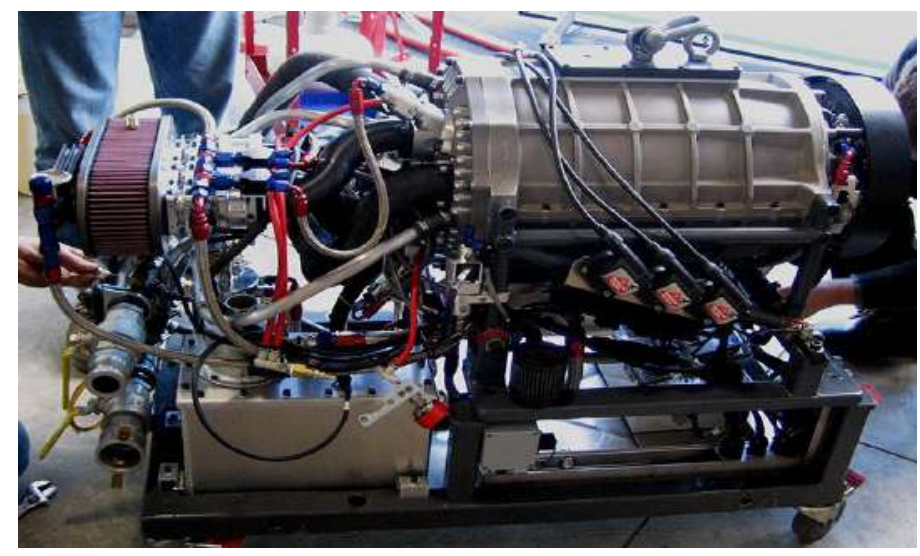

Рисунок 3 - Внешний вид двигателя Duke Engines

Третий образец. Четырехтактный двигатель Duke Engines производство Новая Зеландия является разновидностью аксиальных агрегатов - пятицилиндровый четырёхтактник рабочим объёмом 3 литра. Внешний вид данного агрегата представлен на рисунке 3.

По сравнению с классическим ДВС того же литража он на 19\% легче и на 36\% компактнее. Опытный образец данного двигателя был продемонстрирован в 2018 году на автосалоне в г. Женеве и вызвал интерес у автопроизводителей.

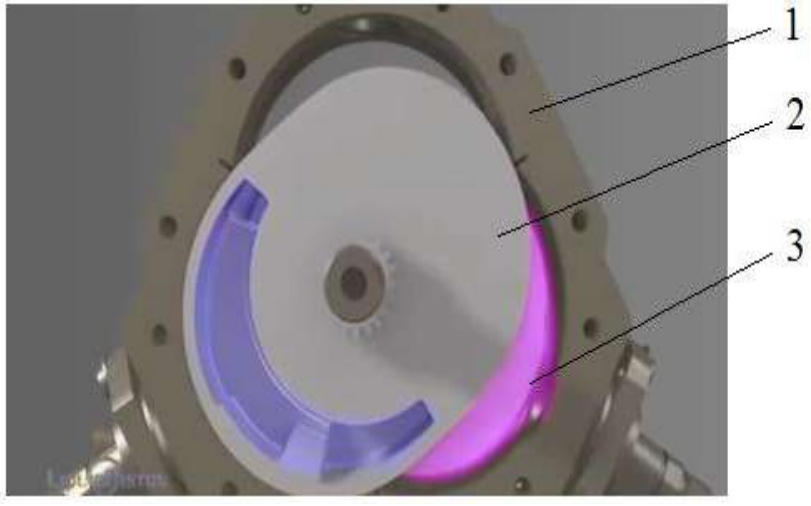

1 - статор; 2 - ротор; 3 - камера сгорания

Рисунок 4 - Принципиальная схема роторного двигателя Liquidpiston

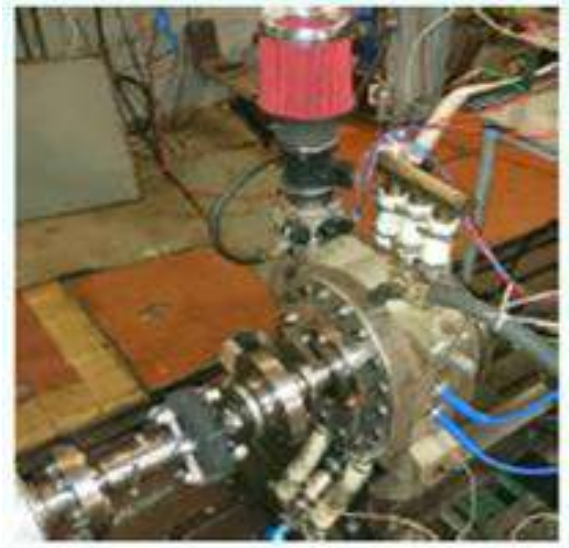

Рисунок 5 - Внешний вид роторнопоршневого двигателя 
Четвертый образец. Роторный двигатель Liquidpiston - производство США. Идея роторных агрегатов различного типа все еще привлекает инженеров. Инженер в США, разработал мотор, напоминающий двигатель Ванкеля. Принципиальная схема такого роторного двигателя Liquidpiston представлена на рисунке 4.

В роторе имеется специальная камера, в которой происходит процесс сгорания. Разработанный опытный образец такого двигателя выполнен рабочим объёмом 23 см$^{3}$ и при таких характеристиках и малых габаритах имеет высокий КПД. Авторы нацелены на создание дизельного образца такого двигателя весом не более 13 кг и мощностью около 40 л. с. с целью его установки на гибридное транспортное средство. При этом его КПД, как заверяют конструкторы, должен подняться до $45 \%$.

Пятый образец. На рисунке 5 представлен перспективный роторно-поршневой двигатель опытный образец, которого создан в центральном институте авиационного моторостроения (г. Москва). Основные преимущества такого двигателя представлены в таблице 2. Следует отметить, что при весе всего в 70 кг данный двигатель развивает 100 лошадиных сил (75 кВт).

Таблица 2 - Основные характеристики роторно-поршневого двигателя

\begin{tabular}{|l|c|c|c|}
\hline Мощность, л.с. & 100 & 200 & 300 \\
\hline $\begin{array}{l}\text { Удельный расход } \\
\text { гл.с.ч. }\end{array}$ & 215 & 210 & 210 \\
\hline Вес, кг & 70 & 100 & 135 \\
\hline Ресурс, ч & \multicolumn{3}{|c|}{ не менее 1500 ч } \\
\hline
\end{tabular}

В перспективе разработчики планируют создать 2-х и 3-х секционный роторно-поршневой двигатель в самолетном и вертолетном исполнении с мощностью в 200 и 300 л. с. соответственно. Конструкция двигателя позволяет обеспечить его ресурс в 1500 мото-часов.

Шестой образец. Дизельный поршневой ДВС.

На рисунке 6 представлен внешний вид перспективного дизельного поршневого ДВС, разработанного в этом же институте в г. Москва. Основные данные, имеющиеся по такому двигателю приведены в таблице 3.

Данный двигатель 4-х тактный с оппозитным расположением шести цилиндров. Такое расположение цилиндров позволяет снизить габаритную высоту двигателя и с 3,3 литров получить отдачу в 300 лошадиных сил (220 кВт) при низком расходе топлива по сравнению с аналогами.

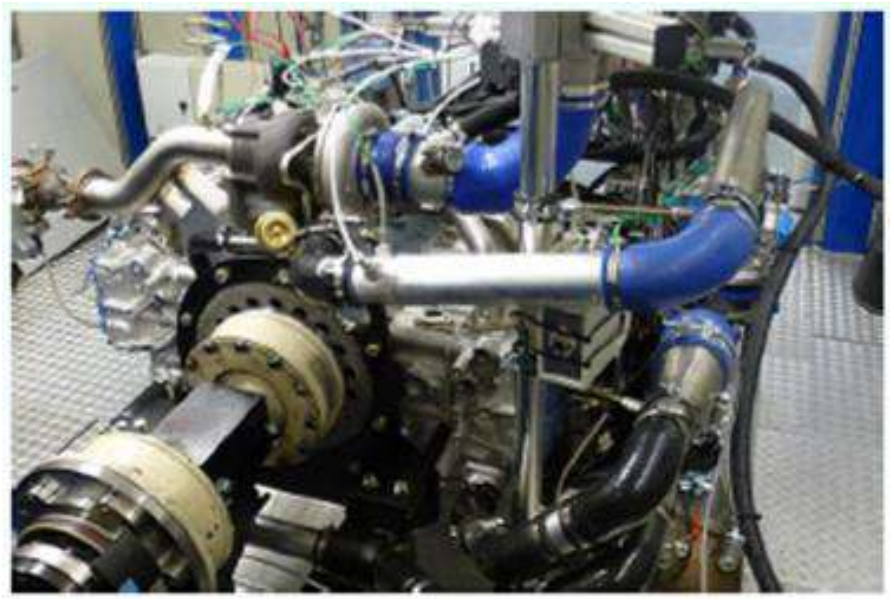

Рисунок 6 - Внешний вид дизельного поршневого ДВС 
Таблица 3 - Основные характеристики дизельного поршневого ДВС

\begin{tabular}{|l|c|}
\hline \multicolumn{1}{|c|}{ Тип } & $\begin{array}{c}\text { Поршневой, четырехтактный, дизельный } \\
\text { жидкостного охлаждения }\end{array}$ \\
\hline Число цилиндров & 6 \\
\hline Расположение цилиндров & Оппозитное \\
\hline Рабочий объем, см ${ }^{3}$ & 3300 \\
\hline Степень сжатия & 17 \\
\hline Мощность (4000 об/мин), л. с. & 300 \\
\hline Удельный расход, г/ л. с. ч & 160 \\
\hline Удельный вес, кг/л. с. & 0,75 \\
\hline
\end{tabular}

Результаты и их обсуждение. На взгляд авторов самая перспективная силовой агрегат для автотракторной техники разработан под руководством профессора Воробьева Ю.В. на кафедре «ТММ и ДМ» Тамбовского государственного технического университета. Созданный многоцелевой роторно-поршневой двигатель (РПД) с круговым параллельным движением роторапоршня, названный «орбитальным» двигателем внутреннего сгорания. В его конструкции совмещены особенности традиционного поршневого ДВС и альтернативного РПД. Такой подход позволяет объединить основные достоинства этих двигателей и устранить присущие им недостатки [4]. Перспективная схема двигателя Воробьева Ю.В. представлена на рисунке 7 а.

На схеме представлены лопасти 8, которые разделяют рабочий объем на изолированные камеры. Данные лопасти шарнирно связаны с ротором-поршнем и совершают сложное движение вокруг статора, перемещаясь в его пазах. Такая конструкция двигателя позволяет сделать уплотнения более надежными и простыми [5].

Рабочий процесс протекает в размещенных по кругу изолированных камерах. Он ничем не отличается от аналогичного процесса в поршневых двигателях внутреннего сгорания. Однако отпадает необходимость в ЦПГ. Отсутствуют верхняя и нижняя мертвые точки в крайних положениях поршня, потому что ротор-поршень располагается на эксцентриковом валу и совершает круговое параллельное движение [6].

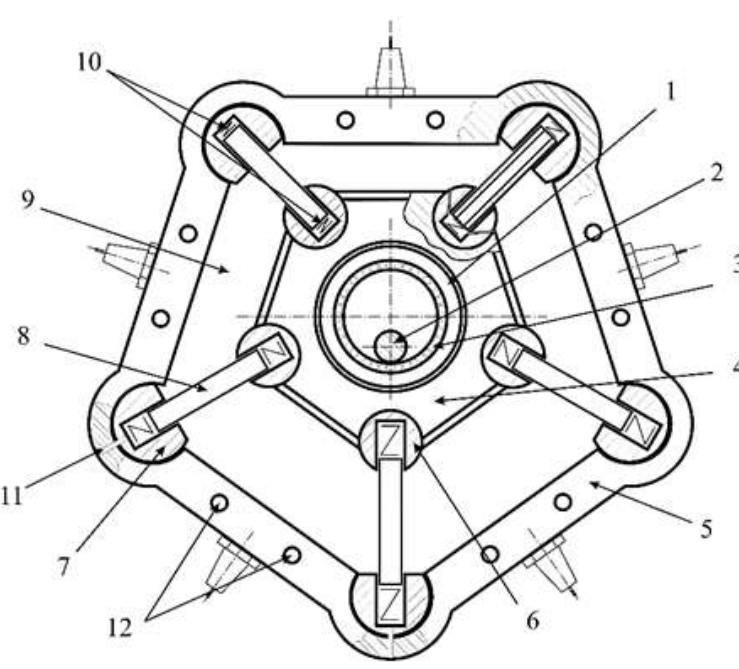

a)

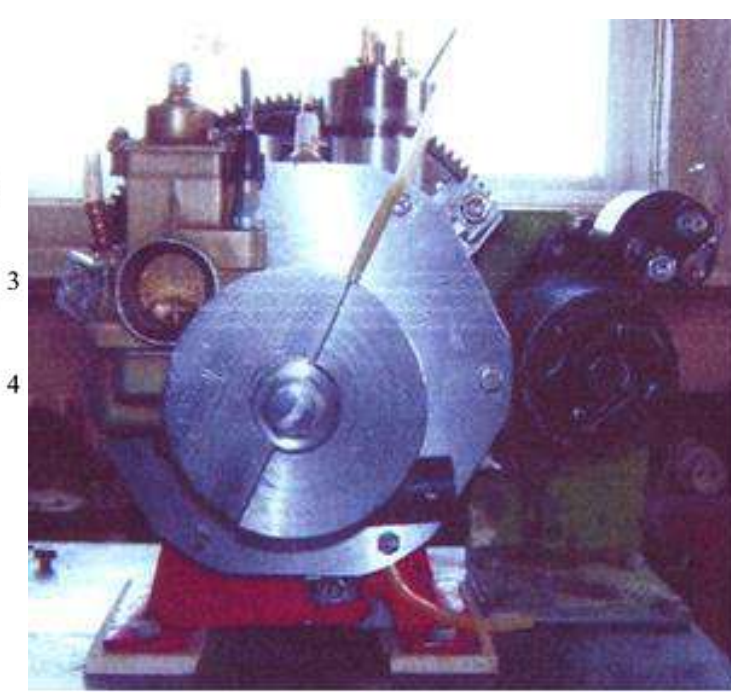

б)

1 - приводной вал (вал отбора мощности); 2 - эксцентрик приводного вала; 3 - подшипник; 4 ротор; 5 - статор; 6 - шарнир ротора - поршня; 7 - шарнир; статора; 8 - лопасть; 9 - рабочие камеры; 10 - элементы, фиксирующие положение лопасти; 11 - канал для подачи смазки; 12 отверстие в статоре для крепления боковых крышек

Рисунок 7 - Схема и внешний вид двигателя Воробьева Ю.В. 
На рисунке 1 б представлен внешний вид созданного в металле трехсекционного двигателя Воробьева Ю.В. с бесклапанной системой газораспределения. Данное решение позволяет упростить уплотнение лопастей в роторе и сделать его более надежным. Двигатель Воробьева Ю.В. конструктивно имеет одно существенное отличие от ДВС Сейрича. В нем идет круговое параллельное движение ротора-поршня, которое реализуется посредством оригинального зубчатого механизма. В таком конструктивном исполнении достигаются наименьшие размеры двигателя в целом.

В связи с этим разработанный двигатель Воробьева Ю.В. имеет следующие преимущества по сравнению с аналогами:

- возможность изменения степени сжатия в таком двигателе;

- $\quad$ возможность использования метало-керамических материалов, что позволит получить существенного снижения расхода топлива и токсичности отработавших газов за счет дискретного изменения его рабочего объема и соответственно повышения КПД такого ДВС.

В предлагаемой конструкции РПД Воробьева Ю.В. повышена герметичность рабочих камер за счет внедрения перспективной конструкции разделительной пластины лопасти, внешний вид которой представлен на рисунке 8 [7].

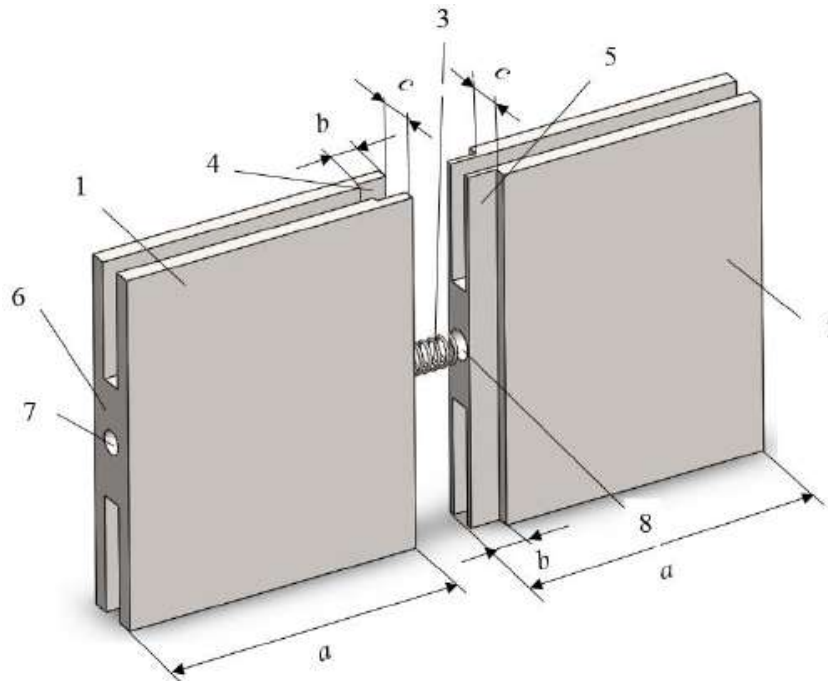

a)

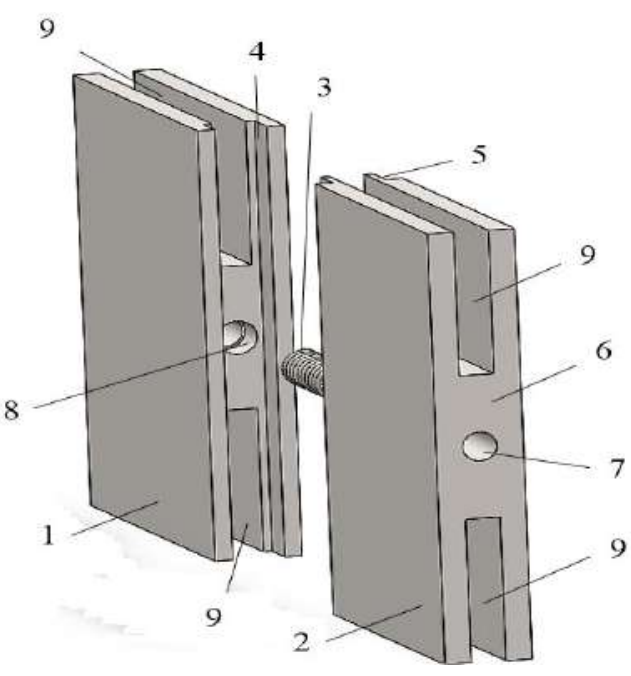

б)

а) вид разделительной пластины сбоку; б) вид разделительной пластины спереди 1, 2 - части разделительной пластины; 3 - упругий элемент; 4 - паз; 5 - шип; 6 - внешняя торцевая поверхность, перпендикулярная оси двигателя, частей разделительной пластины; 7 - отверстие; 8 -

посадочное место под упругий элемент; 9 - паз на торцевой поверхности, параллельной оси двигателя, частей разделительной пластины

Рисунок 8 - Внешний вид разработанной разделительной пластины лопасти

Как видно на рисунке 8 разделительная пластина выполнена составной, состоящей из двух частей, соединенных между собой торцевыми поверхностями, перпендикулярными оси двигателя, с возможностью перемещения относительно друг друга на заданную величину равную:

$$
b=\mathrm{a}-A / 2 \text {, }
$$

где $b$ - заданная величина перемещения двух частей разделительной пластины относительно друг друга; $a$ - длина составной части пластины; $A$ - ширина корпусного элемента двигателя.

При работе РПД обе части пластины перемещаются относительно друг друга вдоль оси двигателя на величину возникающих зазоров и за счет этого обеспечивается постоянное 
прилегание внешних торцевых поверхностей, перпендикулярных оси двигателя. Такое техническое решение позволяет уменьшить утечку газов из рабочих камер РПД, что приведет к возрастанию мощностных и экономических показателей такого двигателя на $10 \ldots 15 \%$ [6].

Созданный профессором Воробьевым Ю.В. опытный образец роторно-поршневого двигателя (рис.8) подтвердил работоспособность представленной конструкции. В ходе его эксплуатации установлено что достигнута заданная степень сжатия $(8,5)$ при 3400 об/мин. Расход топлива на холостом ходу аналогичен этому параметру у мотора ВАЗ 2106, который имеет аналогичный рабочий объем и такой же карбюратор. При этом были отмечены и конструктивные недочеты в системах смазки и охлаждения.

В настоящее время в ВУНЦ ВВС «ВВА» коллективом авторов создана 3-D модель такого двигателя, представленная на рисунке 9, и продолжается работа, начатая профессором Воробьевым Ю.В., по созданию рабочего образца такого двигателя.

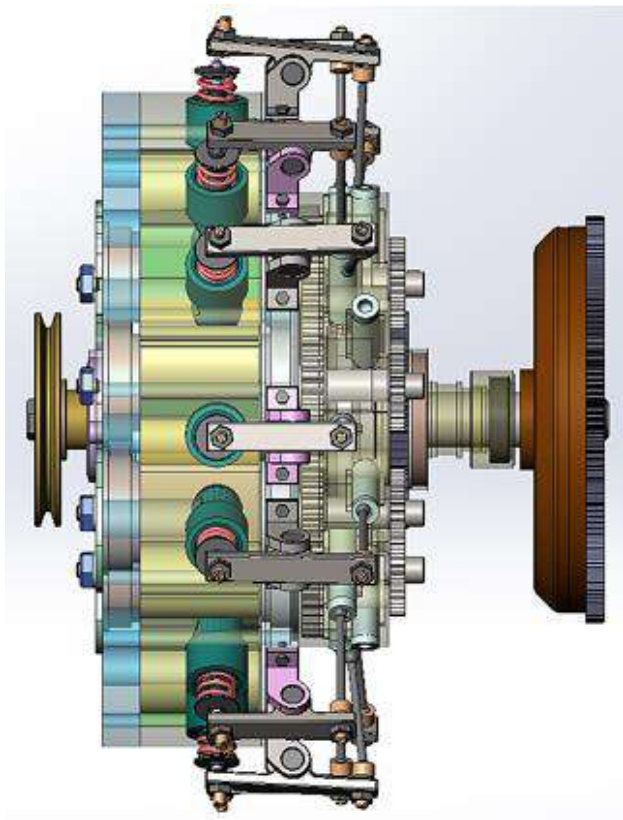

а) роторный двигатель в сборе: главный вид

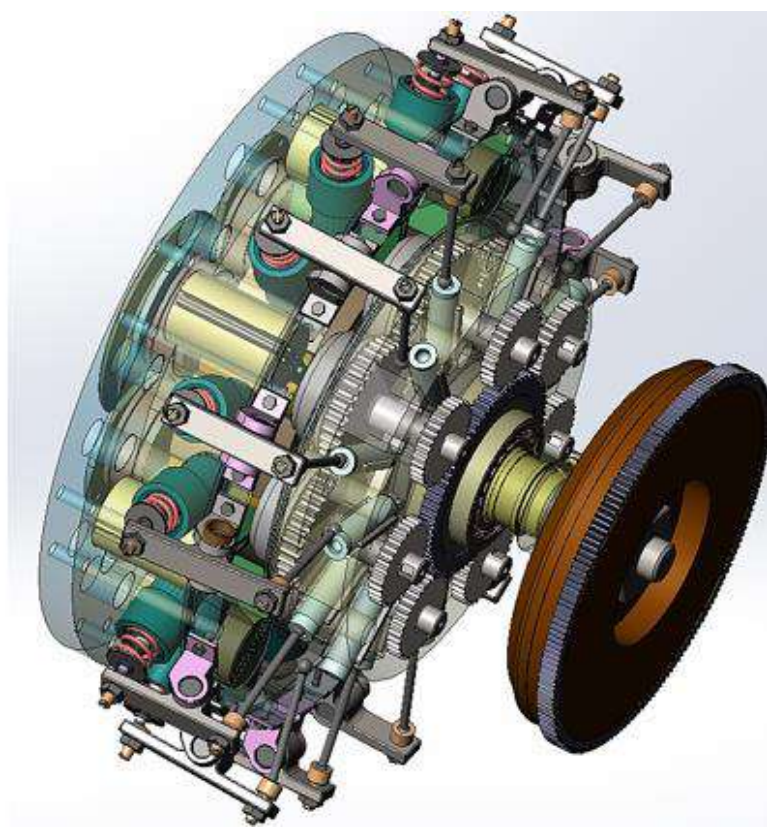

б) роторный двигатель в сборе: вид изометрия

Рисунок 9 - 3-D модель роторного двигателя в сборе

Таким образом, на ближайшую перспективу силовые агрегаты с поршневыми ДВС для АТТ останутся, как основной вид первичных источников энергии, пока запасы нефти позволяют нам эксплуатировать их ближайшие 50 лет.

В связи с этим важным направлением исследований в этой области, наряду с разработкой принципиально новых образцов двигателей в качестве силового агрегата для АТТ, является совершенствование эксплуатируемых двигателей.

В качестве перспектив развития образцов ДВС целесообразно рассмотреть два направления.

1) Увеличения полного КПД ДВС за счет еще не использованных его резервов. В частности, переход от 4-х тактного цикла к 2-х тактному.

2) Устранение внутрицилиндровых противоречий.

Также необходимо рассмотреть перспективные технологии, которые целесообразно использовать в поршневых ДВС, представленные в таблице 4 [8].

Применение указанных решений позволит: снизить удельный расход топлива ДВС до $15 \%$; уменьшить удельный вес до 30\%; увеличить ресурс в 2 раза; снизить вредные выбросы от выхлопных газов двигателей до 40\% [9, 10]. 
Таблица 4 - Перспективные технологии, планируемые к использованию в поршневых ДВС

\begin{tabular}{|c|c|}
\hline Предлагаемые технологии & \\
\hline $\begin{array}{l}\text { 1. Исследование различных схемных реш } \\
\text { для двигателей внутреннего сгорания }\end{array}$ & $\begin{array}{l}\text { ий Снижение массово-габаритных характ } \\
\text { при высоких удельных показателях }\end{array}$ \\
\hline \begin{tabular}{|l}
.$\quad$ Использование \\
турбокомпаундных схем
\end{tabular} & $\begin{array}{l}\text { и Снижение удельного расхода и повышение } \\
\text { мощности силовой установки }\end{array}$ \\
\hline 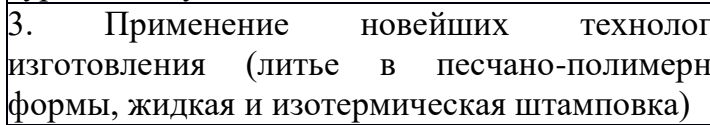 & $\begin{array}{lllr}\text { ий Снижение } & \text { массовых } & \text { характеристик } & \text { и } \\
\text { sе уменьшение } & \text { сроков } \quad \text { создания } & \text { двигателя } & \text { при } \\
\text { увеличении ресурса } & & & \\
\end{array}$ \\
\hline \begin{tabular}{|lcl} 
4. $\quad$ Широкое $\quad$ внедрение & композитных \\
неметаллических & материалов \\
керамика, углепластики) & \\
\end{tabular} & $\begin{array}{l}\text { ие потерь на трение. Снижение весовых } \\
\text { ристик при увеличении ресурса }\end{array}$ \\
\hline Применение альтернативных видов топлив & $\begin{array}{l}\text { атации и } \\
\text { к }\end{array}$ \\
\hline
\end{tabular}

В связи с чем для успешного развития поршневых ДВС в Российской Федерации необходима дальнейшая поддержка со стороны Государства, необходимо возродить научные школы двигателестроения и увеличить потребление поршневых двигателей на внутреннем рынке [11].

Из всего перечисленного можно сделать вывод, что современный двигатель для АТТ с целью эффективного своего функционирования должен быть:

- многотопливным;

- с изменяемой степенью сжатия;

- $\quad$ с рециркуляцией отработавших газов;

- с наддувом и промежуточным охлаждением нагнетаемого воздуха;

- $\quad$ с турбокомпаундной системой;

- с н низкими массово-габаритными характеристиками при высоких удельных показателях;

- $\quad$ п применением биосистем и искусственного интеллекта для управления рабочими циклами двигателя, с целью его адаптации к меняющимся условиям эксплуатации.

Для реализации такого двигателя концепция развития поршневых ДВС в качестве силового агрегата для АТТ в агропромышленном комплексе должна включать следующие этапы:

- проведение комплексных НИР с целью создания научно-технических заданий;

- создание головного научно-инженерного центра и определение первоочередных инновационных проектов;

- $\quad$ разработка нормативно-технической документации для создания и эксплуатации перспективных поршневых двигателей;

- структуризация производителей двигателей, комплектующих для них и обрабатывающих предприятий;

- организация государственной поддержки для значимых проектов;

- выполнение комплексных ОКР, включающих создание базового модельного ряда поршневых двигателей и т.д.

Заключение. Также необходим поиск новых подходов к проблеме совершенствования эксплуатируемых двигателей, особенно Российского производства, которые морально и физически устарели. Для достижения высоких показателей таких двигателей необходимо развиваться по следующим направлениям.

1) Повышение эффективности рабочего цикла двигателя:

- применение системы воздухоснабжения с изменяемой геометрией;

- применение управляемых фаз газораспределения и т.д.;

- модернизация системы топливоподачи;

- применение альтернативных видов топлив для эксплуатируемых ДВС АТТ с целью повышения их экономических и экологических характеристик;

- форсирование ДВС за счет наддува и промежуточного охлаждения воздуха.

2) Совершенствование системы выпуска с целью нейтрализации отработавших газов: 
- применение каталитических нейтрализаторов и сажевых фильтров;

- применение системы рециркуляции выхлопных газов EGR;

- применение перспективных турбокомпаундных установок.

3) Совершенствование механической части ДВС:

- повышением качества изготовления деталей разрабатываемых перспективных двигателей;

- использование новых композитных материалов и металлокерамики.

\section{Список литературы}

1. Распоряжение Правительства РФ № 831-р от 28 апреля 2018 г. «Об утверждении Стратегии развития автомобильной промышленности РФ на период до 2025 года».

2. Устинович С.В. Сравнение поршневого и роторных двигателей внутреннего сгорания // Роторный двигатель (ротор-мотор): - Режим доступа: URL: http://roto-motor.com (дата обращения: 15.10.2020).

3. Альтернативные двигатели внутреннего сгорания: монография / А.Е. Ломовских, Ю.В. Воробьев, В.П. Иванов, Ю.В. Гусев. - Воронеж: ВУНЦ ВВС «ВВА», 2017. - 216 с.

4. Ломовских А.Е., Шаповалов А.А. Многоцелевой, перспективный ДВС орбитального типа для беспилотных летательных аппаратов // Сборник статей по материалам докладов XXIII Всероссийская НТК (26 июня 2014 г.) Серпухов Московской обл.: филиал ВА РВСН. - Серпухов, 2014. - Ч. 7. - С. 73-77.

5. Исследование и разработка предложений по совершенствованию конструкции двигателей внутреннего сгорания роторного типа для привода силовых агрегатов перспективного блочномодульного комплекса средств наземного обслуживания общего применения: отчёт о НИР (заключительный): шифр «Ротор-2» / А.Е. Ломовских и др. - Москва: в/ч 73811, 2017. - 186 с.

6. Патент №2285126 Российской Федерации МПК F01C 1/39, F02B 55/02. Орбитальный двигатель внутреннего сгорания: №2004130817/06, опубл. 10.10.2006. / Воробьев Ю.В., Тетерюков В.Б. $-26 \mathrm{c}$.

7. Патент на полезную модель №199656 Российской Федерации МПК F01C 1/38, F01C 1/38, F01C 19/00. Разделительная пластина лопасти роторного двигателя внутреннего сгорания: №2020114153, опубл. 11.09.2020. / Ломовских А.Е., Илларионов В.В. - 7 с.

8. Грузовик: журнал: - 2020. - №6. - 84 с.

9. Разработка устройств для модернизации системы питания дизельных двигателей внутреннего сгорания с целью улучшения эксплуатационных свойств моторного топлива, применяемого на средствах наземного обслуживания общего применения: отчёт о НИР (заключительный): шифр «Сиспит» / А.Е. Ломовских и др. - Москва: в/ч 73811, 2015. - 148 с.

10. Исследование влияния антифрикционного материала ВПК-АЗ на ресурс силовых двигателей и агрегатов трансмиссии средств наземного обслуживания воздушных судов авиации, эксплуатирующихся в Арктическом регионе Российской Федерации: отчёт о НИР (заключительный): шифр «Смазка» / А.Е. Ломовских и др. - Москва: в/ч 73811, 2019. - 160 с.

11. Долинский А.А., Иваницкий Г.К. Принципы разработки новых энергосберегающих технологий и оборудования на основе методов дискретно-импульсного ввода энергии // Пром. Теплотехника. - 1997. - Т.19., № 4-5. - С. 13-25.

\section{References}

1. Rasporyazhenie Pravitel'stva RF № 831-r ot 28 aprelya 2018 g. «Ob utverzhdenii Strategii razvitiya avtomobil'noj promyshlennosti RF na period do 2025 goda».

2. Ustinovich S.V. Sravnenie porshnevogo i rotornyh dvigatelej vnutrennego sgoraniya // Rotornyj dvigatel' (rotor-motor): - Rezhim dostupa: URL: http://roto-motor.com (data obrashcheniya: 15.10.2020).

3. Al'ternativnye dvigateli vnutrennego sgoraniya: monografiya / A.E. Lomovskih, YU.V. Vorob'ev, V.P. Ivanov, YU.V. Gusev. - Voronezh: VUNC VVS «VVA», 2017. - 216 s.

4. Lomovskih A.E., SHapovalov A.A. Mnogocelevoj, perspektivnyj DVS orbital'nogo tipa dlya bespilotnyh letatel'nyh apparatov // Sbornik statej po materialam dokladov HKHIII Vserossijskaya NTK (26 iyunya 2014 g.) Serpuhov Moskovskoj obl.: filial VA RVSN. - Serpuhov, 2014. - CH. 7. - S. 73-77.

5. Issledovanie i razrabotka predlozhenij po sovershenstvovaniyu konstrukcii dvigatelej vnutrennego sgoraniya rotornogo tipa dlya privoda silovyh agregatov perspektivnogo blochno-modul'nogo kompleksa sredstv nazemnogo obsluzhivaniya obshchego primeneniya: otchyot o NIR (zaklyuchitel'nyj): shifr «Rotor-2»/ A.E. Lomovskih i dr. - Moskva: v/ch 73811, 2017. - 186 s. 
6. Patent №2285126 Rossijskoj Federacii MPK F01C 1/39, F02B 55/02. Orbital'nyj dvigatel' vnutrennego sgoraniya: №2004130817/06, opubl. 10.10.2006. / Vorob'ev YU.V., Teteryukov V.B. - 26 s.

7. Patent na poleznuyu model' №199656 Rossijskoj Federacii MPK F01C 1/38, F01C 1/38, F01S 19/00. Razdelitel'naya plastina lopasti rotornogo dvigatelya vnutrennego sgoraniya: №2020114153, opubl. 11.09.2020. / Lomovskih A.E., Illarionov V.V. - 7 s.

8. Gruzovik: zhurnal: - 2020. - №6. -84 s.

9. Razrabotka ustrojstv dlya modernizacii sistemy pitaniya dizel'nyh dvigatelej vnutrennego sgoraniya s cel'yu uluchsheniya ekspluatacionnyh svojstv motornogo topliva, primenyaemogo na sredstvah nazemnogo obsluzhivaniya obshchego primeneniya: otchyot o NIR (zaklyuchitel'nyj): shifr «Sispit» / A.E. Lomovskih i dr. - Moskva: v/ch 73811, 2015. - 148 s.

10. Issledovanie vliyaniya antifrikcionnogo materiala VPK-AZ na resurs silovyh dvigatelej i agregatov transmissii sredstv nazemnogo obsluzhivaniya vozdushnyh sudov aviacii, ekspluatiruyushchihsya v Arkticheskom regione Rossijskoj Federacii: otchyot o NIR (zaklyuchitel'nyj): shifr «Smazka» / A.E. Lomovskih i dr. - Moskva: v/ch 73811, 2019. - 160 s.

11. Dolinskij A.A., Ivanickij G.K. Principy razrabotki novyh energosberegayushchih tekhnologij i oborudovaniya na osnove metodov diskretno-impul'snogo vvoda energii // Prom. Teplotekhnika. - 1997. - T.19., № 4-5. - S. 13-25.

\section{Сведения об авторах Принадлежность к организации}

Ломовских Александр Егорович - кандидат технических наук, доцент Федерального государственного казенного военного образовательного учреждение высшего образования «Военный учебно-научный центр Военно-воздушных сил «Военно-воздушная академия имени профессора Н.Е. Жуковского и Ю.А. Гагарина» Министерства обороны Российской Федерации, Россия, г. Воронеж, e-mail: lomovskih1979@yandex.ru.

Сазонов Сергей Николаевич - доктор технических наук, профессор, Администрация Тамбовской области, Россия, г. Тамбов, e-mail: snsazon@mail.ru

Новичихин Виталий Васильевич - соискатель Федерального государственного казенного военного образовательного учреждение высшего образования «Военный учебно-научный центр Военно-воздушных сил «Военно-воздушная академия имени профессора Н.Е. Жуковского и Ю.А. Гагарина» Министерства обороны Российской Федерации, Россия, г. Воронеж, oskol20@ mail.ru.

Калинин Никита Сергеевич - курсант Федерального государственного казенного военного образовательного учреждение высшего образования «Военный учебно-научный центр Военновоздушных сил «Военно-воздушная академия имени профессора Н.Е. Жуковского и Ю.А. Гагарина» Министерства обороны Российской Федерации, Россия, г. Воронеж.

Машин Владимир Алексеевич - курсант Федерального государственного казенного военного образовательного учреждение высшего образования «Военный учебно-научный центр Военновоздушных сил «Военно-воздушная академия имени профессора Н.Е. Жуковского и Ю.А. Гагарина» Министерства обороны Российской Федерации, Россия, г. Воронеж.

\section{Authors credentials}

\section{Affiliations}

Lomovskih Alexandr - candidate of technical sciences, associate professor of the department, Military educational scientific center air force «air force Academy named after Professor N. E. Zhukovsky and Y. A. Gagarin», Russia, Voronezh, e -mail: lomovskih1979@yandex.ru.

Sazonov Sergey - Doctor of technical Sciences, Professor, Administration of the Tambov region, Russia, Tambov.

Novichikhin Vitaly - associate of the academy, Military educational scientific center air force «air force Academy named after Professor N. E. Zhukovsky and Y. A. Gagarin», Russia,Voronezh, e -mail: oskol20@mail.ru.

Kalinin Nikita - cadet of the academy, Military educational scientific center air force «air force Academy named after Professor N. E. Zhukovsky and Y. A. Gagarin», Russia,Voronezh.

Mashin Vladimir - cadet of the academy, Military educational scientific center air force «air force Academy named after Professor N. E. Zhukovsky and Y. A. Gagarin», Russia,Voronezh.

Поступила в редакцию (Received): 08.09.2021 Принята к публикации (Accepted): 15.10.2021 